\title{
Lactobacillus plantarum induces innate cytokine responses that potentially provide a protective benefit against COVID-19: A single-arm, double-blind, prospective trial combined with an in vitro cytokine response assay
}

\author{
YASUNARI KAGEYAMA ${ }^{1,2}$, YASUHIRO NISHIZAKI ${ }^{2,3}$, KOICHI AIDA $^{1}$, KATSUYUKI YAYAMA $^{1}$, \\ TOMOKA EBISUI ${ }^{1}$, TETSU AKIYAMA ${ }^{4}$ and TSUTOMU NAKAMURA ${ }^{1,4}$ \\ ${ }^{1}$ Takanawa Clinic, Tokyo 108-0074; ${ }^{2}$ Tokai University Hospital, Isehara-shi, Kanagawa 259-1193; \\ ${ }^{3}$ Department of Clinical Health Science, Tokai University Tokyo Hospital, Tokai University School of \\ Medicine, Tokyo 151-0053; ${ }^{4}$ Laboratory of Molecular and Genetic Information, Institute for Quantitative Biosciences, \\ The University of Tokyo, Tokyo 113-0032, Japan
}

Received March 31, 2021; Accepted September 22, 2021

DOI: $10.3892 / \mathrm{etm} .2021 .10942$

\begin{abstract}
Intestinal microbiota can indirectly modulate airway physiology and immunity through the gut-lung axis. Recent microbiome studies indicate that patients with coronavirus disease 2019 (COVID-19) exhibit a specific intestinal dysbiosis that is closely associated with the disease pathophysiology. Therefore, rebalancing the intestinal microbiome using probiotics may be effective for controlling COVID-19. However, the rationale for using probiotics in COVID-19 remains unclear. In the present study, an in vitro cytokine response assay was conducted, followed by a single-arm, double-blind, prospective trial to evaluate the immunological efficacy of probiotic lactic acid bacteria against COVID-19. The present study focused on Lactobacillus plantarum (L. plantarum), Bifidobacterium longum and Lactococcus lactis ssp. lactis, which exhibit
\end{abstract}

Correspondence to: Dr Tsutomu Nakamura, Laboratory of Molecular and Genetic Information, Institute for Quantitative Biosciences, The University of Tokyo, 1-1-1 Yayoi, Bunkyo-ku, Tokyo 113-0032, Japan

E-mail: nakamura@iqb.u-tokyo.ac.jp

Abbreviations: QFPD, Qingfei Paidu decoction; ACE2, angiotensin-converting enzyme 2; TMPRSS2, transmembrane serine protease 2; LAB, lactic acid bacteria; QICI, QFPD-induced innate cytokine index; IFN, interferon; FSC, forward scatter; SSC, side scatter; NK, natural killer; IQR, interquartile range; BALF, bronchoalveolar lavage fluid; TLR, toll like receptor; NLRP3, NLR family pyrin domain containing 3; ssRNA, single-stranded RNA

Key words: coronavirus disease 2019, cytokines, dysbiosis, gut-lung axis, lactic acid bacteria, Lactobacillus plantarum, microbiota, natural killer cells, probiotics, severe acute respiratory syndrome coronavirus 2 robust protective effects against infection with respiratory RNA viruses. Considering the feasibility of long-term daily intake for prophylactic purposes, healthy uninfected individuals were enrolled as subjects. Our previous pilot trial demonstrated that oral Qingfei Paidu decoction (QFPD), a Chinese herbal medicine formulated specifically against COVID-19, upregulates plasma TNF- $\alpha$, IL-1 $\beta$, IL-18 and IL-8. Therefore, the present study utilized the cytokine changes induced by QFPD to define the innate cytokine index QICI $[=(\mathrm{TNF}-\alpha) \times(\mathrm{IL}-1 \beta) \times(\mathrm{IL}-18) \times(\mathrm{IL}-8) /(\mathrm{IL}-6)]$ as an indicator of the anti-COVID-19 immunomodulatory potential of the lactic acid bacteria. A total of 20 eligible volunteers were enrolled, 18 of whom completed the intervention. L. plantarum demonstrated a strikingly high innate cytokine index in all subjects in the in vitro cytokine response assay. In the subsequent trial, oral intake of L. plantarum significantly increased the innate cytokine index (mean fold change, 17-fold; $\mathrm{P}=0.0138$ ) and decreased the plasma level of IL-6 $(\mathrm{P}=0.0128)$, a key driver of complex immune dysregulation in COVID-19, as compared with the baseline. The cytokine index increased in 16 of 18 subjects $(88.9 \%)$ with considerable individual differences in the fold change (1- to 128-fold). In line with these innate cytokine changes, L. plantarum ingestion significantly enhanced the activity of natural killer cells. By contrast, oral B. longum failed to induce a significant increase in the innate cytokine index (mean fold change, 2-fold; $\mathrm{P}=0.474$ ) as compared with the baseline. In conclusion, L. plantarum demonstrated superior QFPD-like immunomodulatory ability and mimicked the blood cytokine environment produced by early immune responses to viral infection. Daily consumption of L. plantarum as an anti-COVID-19 probiotic may be a possible option for preventing COVID-19 during the pandemic. The present study was prospectively registered in the University Hospital Medical Information Network-Clinical Trials Registry under the trial number UMIN000040479 on 22 May 2020 (https://upload.umin.ac.jp/cgi-open-bin/ctr_e/ctr_ view.cgi?recptno=R000046202). 


\section{Introduction}

The coronavirus disease 2012 (COVID-19) pandemic is becoming an increasingly serious threat to global public health. The causative coronavirus, severe acute respiratory syndrome coronavirus 2 (SARS-CoV-2), primarily infects a subpopulation of airway epithelial cells that co-express the viral entry molecules angiotensin-converting enzyme 2 (ACE2) and transmembrane serine protease 2 (TMPRSS2) (1-3). Notably, several lines of evidence suggest that SARS-CoV-2 can also infect human intestinal epithelial cells, as ACE2 and TMPRSS2 are co-expressed in the lower gastrointestinal tract, particularly enterocytes and progenitor cells of the ileum and colon (2-5). Targeted infection and active replication of SARS-CoV-2 in ACE2-expressing enterocytes have been demonstrated using human intestinal organoids (5-8). SARS-CoV-2 RNA has been detected in stool specimens and anal/rectal swabs of patients with COVID-19 (9-11), and infectious viruses have been isolated from feces of patients (8). A considerable percentage of patients with COVID-19 present with concurrent gastrointestinal symptoms, such as diarrhea and abdominal pain (12-14). These findings raise the possibility that there are adverse effects between the enteric infection of SARS-CoV-2 and the intestinal microbiome.

Gut microbiota serves key roles in the crosstalk between the intestinal and respiratory tracts, which is called the gut-lung axis, via which gut microbe-derived molecules (including structural components, metabolites and toxins, among others) modulate airway physiology and immunity (15-17). Intestinal dysbiosis leads to aberrant immune tone in the airway mucosa, which can trigger dysregulated immune responses to respiratory viral infection (15-17). Recent microbiome studies have revealed that patients with COVID-19 have compositional changes in the specific taxa of enteric bacteria (18-21). Notably, a subset of the changes correlate with the serum levels of proinflammatory cytokines, symptom severity and fecal SARS-CoV-2 virus load, suggesting that COVID-19-related intestinal dysbiosis is closely associated with the disease pathophysiology (19-21).

Numerous animal and clinical studies have demonstrated that the oral intake of probiotic strains of various lactic acid bacteria (LAB) species exhibited prophylactic and therapeutic efficacy against infection by respiratory RNA viruses (22-26). Life-threatening symptoms and complications of COVID-19 are caused by hyperinflammation owing to complex immune dysregulation involving neutrophilia, lymphocytopenia, reduced T-cell immunity and excessive production of inflammatory mediators (27-29). Specific probiotic LAB strains, such as L. plantarum strain DR7 and L. paracasei strain 8700:2, have superior immunomodulatory and anti-inflammatory abilities against respiratory viral infection and may therefore be suitable for therapeutic use $(30,31)$. On the other hand, certain proinflammatory LAB strains are known to induce innate cytokine changes that can trigger early antiviral immune responses and may therefore be employed prophylactically $(32,33)$. Notably, previous preclinical studies and randomized controlled trials have demonstrated that among probiotic LAB, Lactobacillus plantarum (L. plantarum) (33-39), Bifidobacterium longum (B. longum) $(40,41)$ and Lactococcus lactis ssp. Lactis (L. lactis ssp. lactis) (42) exhibit robust protective effects against influenza virus infection through enhancing host innate immunity.

The genera Lactobacillus, Bifidobacterium and Lactococcus are the most representative LAB and have been recognized as having probiotic properties beneficial for the human health $(43,44)$. L. plantarum is a Gram-positive, facultatively anaerobic, rod-shaped bacterium with a plant origin and is distributed in the human intestinal tract and oral cavity. It is a heterofermentative LAB closely associated with various fermented plant foods, such as pickles, sauerkraut and kimchi. B. longum is a Gram-positive, obligatory anaerobic, heterofermentative bacterium with V- or Y-shaped morphology and inhabits the human intestine predominantly from newborns to elderly people. L. lactis ssp. lactis is a Gram-positive, facultatively anaerobic, spherical bacterium commonly present in raw milk and fermented dairy products.

Qingfei Paidu decoction (QFPD), the Chinese word for 'lung cleansing and detoxifying decoction', is a Chinese herbal medicine newly formulated and specifically optimized against COVID-19, and its therapeutic use has been encouraged in the Chinese official management guidelines (45). Clinical trials in China have demonstrated that QFPD accelerated recovery and prevented disease progression in mild to critical cases (46-49). A retrospective clinical study has also indicated that QFPD decreased the blood levels of COVID-19 biomarkers, such as C-reactive protein, creatine kinase and lactate dehydrogenase (50). Our previous study has demonstrated that the pharmacological action of QFPD was associated with the upregulation of the plasma levels of TNF- $\alpha$, IL-1 $\beta$, IL-18 and IL-8, which are key cytokines that mediate early innate immune responses to viral infection (51).

Therefore, rebalancing the gut microbiome using probiotics may be effective for the control of COVID-19. However, to the best of our knowledge, no studies have focused on the efficacy of probiotics in patients with COVID-19, and the rationale for using probiotics against COVID-19 remains unclear. In addition, there is a requirement for investigating diverse prophylactic options owing to the frequent emergence and rapid spread of novel SARS-CoV-2 variants carrying immune escape mutations. To explore the immunological efficacy of probiotics for preventing COVID-19, a single-arm, double-blind, prospective trial combined with an in vitro cytokine response assay was conducted using L. plantarum, B. longum and L. lactis ssp. lactis. The innate cytokine changes induced by QFPD were used as an indicator of the anti-COVID-19 immunomodulatory potential of the LAB. Furthermore, the effects of LAB ingestion on the activity of innate immune cells were examined.

\section{Materials and methods}

Subjects. Participants were recruited through the University Hospital Medical Information Network-Clinical Trials Registry website, Takanawa Clinic (Tokyo, Japan) website, announcements in an e-mail newsletter and personal contacts. Individuals who met all the following inclusion criteria were enrolled: i) Healthy adults between the ages of 20 and 70; and ii) having negative PCR and $\operatorname{IgM} / \operatorname{IgG}$ antibodies tests for SARS-CoV-2 at study entry (no previous and current SARS-CoV-2 infection). Chest imaging tests were not used in 
the present study. Individuals were excluded from this trial if they met any of the following exclusion criteria: i) Pregnant; ii) breastfeeding; iii) duplicate enrollment in other clinical trials; iv) history of infectious disease within 6 months before the enrollment; v) current or past history of chronic inflammatory, immune-related or neoplastic diseases; vi) history of medicinal drug use within 6 months before the enrollment; and vii) underlying conditions associated with higher risk of COVID-19, including hypertension, cardiovascular disease, cerebrovascular disease, diabetes, obesity (body mass index 230) $(52,53)$, chronic obstructive pulmonary disease and chronic kidney disease. Therefore, the enrolled subjects had no recorded and reported comorbidities.

Subject recruitment. In our previous study using QFPD on 18 healthy subjects (51), the effect sizes $\mathrm{r}$ obtained were 0.816 (TNF- $\alpha$ ), 0.881 (IL-1 $\beta$ ), 0.724 (IL-18) and 0.796 (IL-8). The average value of 0.804 was employed as an estimated effect size for the present trial. A priori two-tailed power analysis was conducted with a level of significance $\alpha$ of 0.05 , a desired power $1-\beta$ of 0.8 and the estimated effect size of 0.804 , which suggested a required total sample size of 15 individuals.

Participant recruitment took place between 27 May 2020 and 2 June 2020 at Takanawa Clinic (Tokyo, Japan). A total of 20 volunteers were screened for eligibility, indicated to be eligible and enrolled in the present trial (Fig. 1). In vitro cytokine response assay was performed between 7 and 9 June 2020. LAB were administered to all the enrolled participants between 25 June and 17 August 2020, 2 of whom were excluded from the main analysis due to no visit to Takanawa Clinic following the LAB prescription. Consequently, 18 subjects (1 male and 17 females; age, 28-66 years; mean age \pm SD, 44.2 \pm 10.1 years) completed the intervention, and the data were subjected to statistical analysis.

Study design. The present study comprised two sequential experimental procedures: An in vitro cytokine response assay and a single-arm, double-blind, prospective trial.

The optimal LAB in each subject were determined using co-culture of the peripheral blood with each LAB. QFPD-induced innate cytokine changes were used as an indicator to evaluate the anti-COVID-19 immunomodulatory potential of LAB. The QFPD-induced innate cytokine index (QICI) was defined as follows: $\mathrm{QICI}=(\mathrm{TNF}-\alpha) \times(\mathrm{IL}-1 \beta) \times$ (IL-18) x (IL-8)/(IL-6), where brackets represent the plasma level of the cytokine in $\mathrm{pg} / \mathrm{ml}$. IL-6 is a critical driver of complex immune dysregulation in patients with COVID-19 and was thus adopted as the denominator (54-56).

The LAB with the highest and lowest QICI were used in a subsequent clinical trial to examine whether the ingested $\mathrm{LAB}$ could reproduce the in vitro cytokine responses (in vitro QICI). The trial consisted of three consecutive sessions: i) Validation (intervention using the LAB with the highest QICI); ii) washout; and iii) control (intervention using the LAB with the lowest QICI) sessions. The primary outcome measure was the changes in the plasma levels of TNF- $\alpha$, IL-1 $\beta$, IL-18, IL-8 and IL-6 and the QICI after each 7-day LAB session compared with those at baseline. The secondary outcome measure was the changes in hematological parameters after each 7-day LAB session compared with those at baseline.
In vitro cytokine response assay. L. plantarum SNK $12\left[2 \times 10^{12}\right.$ colony-forming unit/g (cfu/g); Bio-Lab Co., Ltd.] is a probiotic strain with potent immunomodulatory, anti-inflammatory and antiviral abilities $(57,58)$. A probiotic B. longum BB536 strain $\left(1.5 \times 10^{11} \mathrm{cfu} / \mathrm{g}\right.$; Morinaga Milk Industry Co., Ltd.) has been reported to exhibit various clinical benefits, such as anti-allergic effects $(59,60)$, protection against viral infection $(41,61)$ and modulation of gut microbiota (62-64). L. lactis ssp. lactis demonstrates immunomodulatory and antiviral effects through activating plasmacytoid dendritic cells and increasing their ability to produce interferons (IFNs) (42). The commercially available probiotic strain LLL970 (1x10 $11 \mathrm{cfu} / \mathrm{g}$; Synbio Tech, Inc.) was used in the present study.

Live LAB cells were disrupted by vibrating them twice at $4,600 \mathrm{rpm}$ (the number of the figure-8-shaped movement of sample tubes per minute) for $3 \mathrm{~min}$ at room temperature with $0.5 \mathrm{~g}$ of $3.0-\mathrm{mm}$ zirconia beads in a commercial bead vibrator (PS-2000; Kurabo Industries Ltd.) followed by heating at $60^{\circ} \mathrm{C}$ for $20 \mathrm{~min}$. Dead LAB were suspended at a $100 \mu \mathrm{g} / \mathrm{ml}$ concentration in Dulbecco's PBS (without $\mathrm{Ca}^{2+}$ and $\mathrm{Mg}^{2+}$ ).

The ability of the LAB to stimulate QFPD-like cytokine production by peripheral blood immune cells was evaluated as described in previous studies (65-67). Briefly, heparinized peripheral blood $(0.4 \mathrm{ml})$ from each subject was co-cultured with each killed LAB suspension ( $4 \mu \mathrm{g})$ in $1 \mathrm{ml} \mathrm{RPMI-1640}$ medium (DS Pharma Biomedical Co., Ltd.) supplemented with $10 \%$ fetal bovine serum (FBS; Sigma-Aldrich; Merck $\mathrm{KGaA}$ ) in a humidified incubator with $5 \% \mathrm{CO}_{2}$ at $37^{\circ} \mathrm{C}$ for 48 h. Concentrations of TNF- $\alpha$, IL- $1 \beta$, IL- 8 and IL- 6 in culture supernatants were measured using the V-PLEX Proinflammatory Panel 1 Human kit (cat. no. K15049D-1; Meso Scale Diagnostics, LLC) and the concentration of IL-18 was measured using the Human IL-18 ELISA kit (cat. no. ab215539; Abcam) according to the manufacturers' protocols. The data were used to calculate the QICI value for the characterization of the species with the highest or lowest QICI.

Clinical trial. The present trial was a single-arm, double-blind, prospective trial. Each subject was instructed to orally ingest the live LAB with the highest QICI $\left(1 \times 10^{11} \mathrm{cfu} /\right.$ day $)$ in the in vitro cytokine response assay twice daily in the morning and evening between meals for 7 days (days 1-7). After a 7-day washout period (days 8-14), a negative control trial was conducted, in which the LAB with the lowest QICI in the in vitro cytokine response assay $\left(1 \times 10^{11} \mathrm{cfu} / \mathrm{day}\right)$ was orally administered twice daily in the morning and evening between meals for 7 days (days 15-21). Peripheral blood samples were obtained from each subject on days 0,8 and 22 . Neither the subjects nor physicians in charge were aware of the results of the in vitro $\mathrm{LAB}$ assessment, prescribed LAB or their QICI properties until the final blood sampling was completed. Concentrations of plasma TNF- $\alpha$, IL- $1 \beta$, IL-18, IL-8 and IL-6 were quantified as aforementioned. Hematological and blood biochemical tests (parameters as listed in Table SII) were outsourced to SRL, Inc.

Innate immune cell activity assays. A total of $\sim 9$ months after the completion of the trial, 10 healthy subjects were randomly selected from the 18 trial participants and randomly assigned 


\section{O N S O R T}

TRANSPARENT REPORTING of TRIALS

CONSORT 2010 Flow diagram

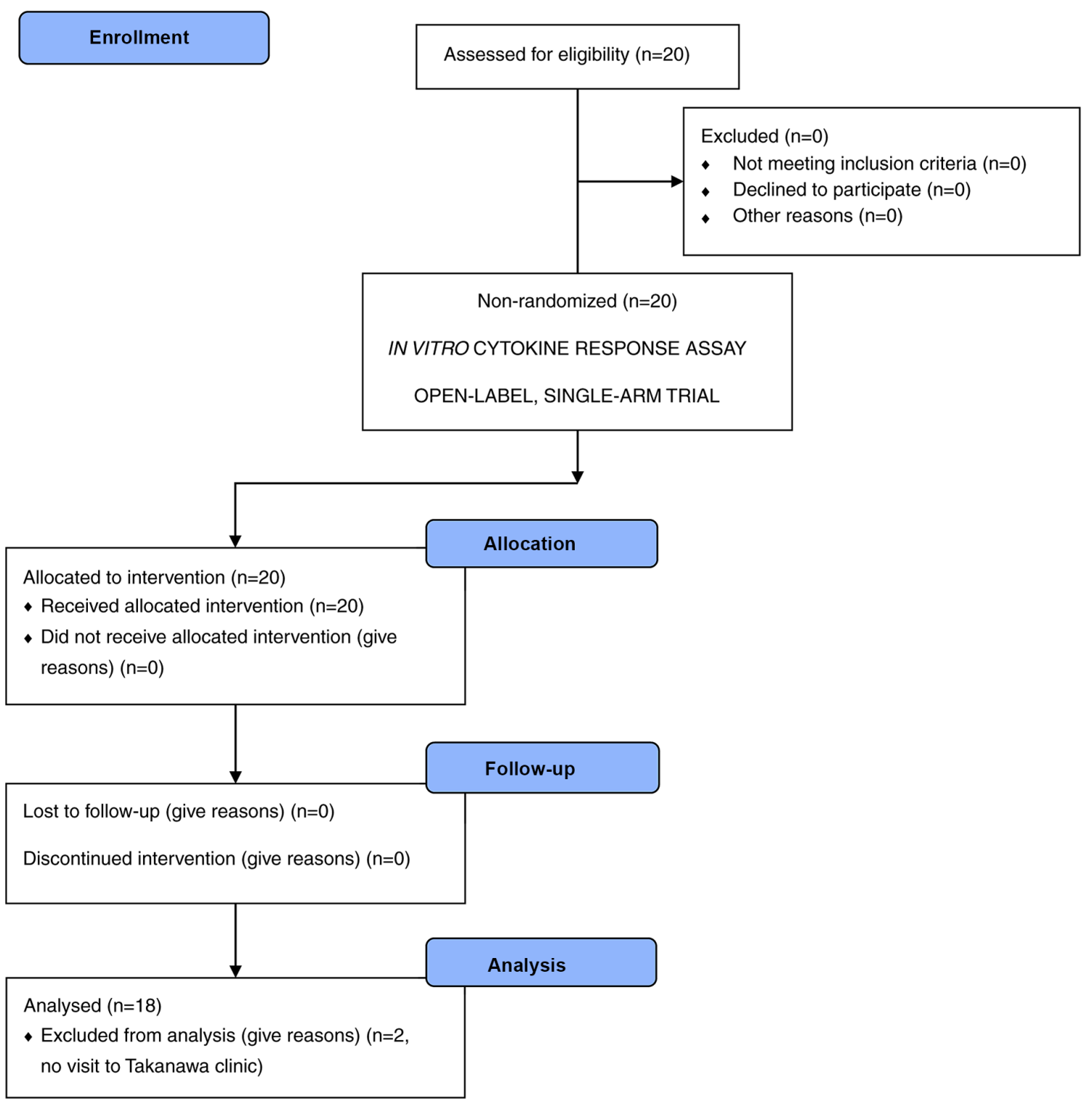

Figure 1. CONSORT flow diagram of participants in the present study. CONSORT; consolidated standards of reporting trials.

to either the L. plantarum group ( $\mathrm{n}=5)$ or the B. longum group $(\mathrm{n}=5)$ through simple randomization. Ingestion of $L$. plantarum and B. longum and blood sampling were conducted with the same protocol as that of the trial $\left(1 \times 10^{11} \mathrm{cfu} /\right.$ day; twice daily for 7 days). After a 7-day ingestion, innate immune cell activity was measured using standard methods as described below in detail.

Neutrophil activity. Measurement of the phagocytic activity of neutrophils was outsourced to BML, Inc. Briefly, heparinized peripheral blood $(0.1 \mathrm{ml})$ from each subject was mixed with $40 \mu$ l fluorescent microbeads (Fluoresbrite ${ }^{\circledR}$ YG Carboxylate Microspheres $1.75 \mu \mathrm{m}$; Polysciences, Inc.) diluted 4-fold with Dulbecco's PBS [-(without $\mathrm{Ca}^{2+}$ and $\left.\mathrm{Mg}^{2+}\right)$ ] and incubated with gentle agitation at $37^{\circ} \mathrm{C}$ for $30 \mathrm{~min}$. The samples were treated with $2 \mathrm{ml} 10 \mathrm{X}$ FACS lysing solution (BD Biosciences) at $4^{\circ} \mathrm{C}$ for $15 \mathrm{~min}$ to lyse erythrocytes under gentle hypotonic conditions, followed by flow cytometric analysis using FACSCalibur ${ }^{\mathrm{TM}}$ flow cytometer (BD Biosciences). Granulocytes were characterized as medium-sized cells with high granularity and 
separated by setting a medium forward scatter (FSC)/high side scatter (SSC) gating. The percentage of fluorescence-positive granulocytes (granulocytes that phagocytosed the fluorescent microbeads) to the total count of granulocytes was calculated using the BD CellQuest ${ }^{\mathrm{TM}}$ Pro software version 6.0 (BD Biosciences).

Natural killer $(N K)$ cell activity. Analysis of NK cell activity using chromium-51 $\left({ }^{51} \mathrm{Cr}\right)$ release assay was outsourced to SRL, Inc. Lymphocytes were isolated from $5 \mathrm{ml}$ peripheral blood using density gradient centrifugation (Lymphosepar I; Immuno-Biological Laboratories Co., Ltd.) according to the manufacturer's instructions. The lymphocytes were washed twice with Dulbecco's PBS (-) and resuspended at $1 \times 10^{6}$ cells $/ \mathrm{ml}$ in RPMI-1640 supplemented with $10 \%$ FBS. A total of $200-\mu 1$ aliquots (effector cells; $2 \times 10^{5}$ ) were mixed with human chronic myelogenous leukemia K562 cells (target cells; $1 \times 10^{4}$ cells/10 $\mu \mathrm{l}$; cat. no. CCL-243; American Type Culture Collection) radiolabeled with ${ }^{51} \mathrm{Cr}$ (PerkinElmer, Inc.) and incubated at $37^{\circ} \mathrm{C}$ for $3.5 \mathrm{~h}$ in a $5 \% \mathrm{CO}_{2}$ incubator. The cells were collected by centrifugation, and the remaining ${ }^{51} \mathrm{Cr}$ radioactivity was measured using WIZARD ${ }^{\circledR}$ Automatic Gamma Counter (PerkinElmer, Inc.). ${ }^{51} \mathrm{Cr}$-loaded K562 cells treated with effector-free culture medium (RPMI-1640; $10 \%$ FBS) were used for the quantification of spontaneously released ${ }^{51} \mathrm{Cr}$.

Macrophage activity. The serum level of neopterin, an activation marker produced primarily by IFN- $\gamma$-stimulated monocytes and macrophages $(68,69)$, was assessed for macrophage activity. Determination of serum neopterin was outsourced to SRL, Inc. Serum $(0.3 \mathrm{ml})$ was analyzed by a reverse-phase high-performance liquid chromatography column-switching method (LC-2000Plus; JASCO Corporation) (70) using Wakosil GP-N6 4.6x150 mm as a pretreatment column and Wakosil-II 5C18 HG 4.6x250 mm as an analysis column (FUJIFILM Wako Pure Chemical Corporation). The neopterin level was determined by detecting its native fluorescence (excitation, $353 \mathrm{~nm}$; emission, $438 \mathrm{~nm}$ ) with a fluorescence detector (FP-2025; JASCO Corporation).

Statistical analysis. For the in vitro cytokine response assay, when IL-1 $\beta$ was undetectable in negative control samples (14 of 20 enrolled subjects; Table SI), $0.5 x$ lower limit of detection $(0.05 \mathrm{pg} / \mathrm{ml})$ was used to calculate the QICI value.

In the analysis of the trial data, the interquartile range (IQR) method was used to identify outliers; any values that fell below Q1-1.5x IQR or above Q3 + 1.5x IQR (Q1, first quartile; $\mathrm{Q} 3$, third quartile) were considered outliers and removed from the statistical analysis $(71,72)$. In order to perform statistical tests of matched pairs, the paired values of the outliers were removed, even if they fell into the non-outlier range. When calculating QICI scores, outliers and zero values were handled as follows: i) The outliers were replaced with mean values that were calculated from the non-outliers to avoid unreasonable reduction of QICI scores by simple removal of the outliers; and ii) zero values in the measurement of IL- $1 \beta$ and IL-18 were replaced with the values of $0.5 x$ lower limit of detection (IL-1 $\beta, 0.05 \mathrm{pg} / \mathrm{ml}$; IL-18, $8.30 \mathrm{pg} / \mathrm{ml})(73,74)$.
The normality of the data was firstly examined using the normal quantile-quantile plots and the Shapiro-Wilk test. On the basis of the results from these normality tests, the Friedman test was used, followed by the Nemenyi post hoc test for the data from the clinical trial; a two-tailed paired Student's t-test was used for the data from the assays of innate immune cell activity.

All statistical analyses were performed with EZR v1.53 (Saitama Medical Center, Jichi Medical University), which is a graphical user interface for $\mathrm{R}$ ( $\mathrm{R}$ Foundation for Statistical Computing; https://www.R-project. org/) (75). A priori sample size calculation and post hoc power analysis were performed using $\mathrm{G}^{*}$ Power v3.1.9.2 (Department of Experimental Psychology, Heinrich Heine University Düsseldorf; https://www.psychologie.hhu. de/arbeitsgruppen/allgemeine-psychologie-und-arbeitspsychologie/gpower) (76). Spearman's rank correlation coefficients for the post hoc power analysis were calculated with EZR v1.53 (75). $\mathrm{P}<0.05$ was considered to indicate a statistically significant difference.

\section{Results}

Selection of LAB with the highest and lowest QICI. Firstly, the species with the highest and lowest QICI among the three probiotic LAB (L. plantarum, B. longum and L. lactis ssp. lactis) were determined in each of the 20 study subjects, using in vitro cytokine response assay. L. plantarum demonstrated the highest QICI in all subjects, whereas B. longum demonstrated the lowest QICI (Table SI). L. plantarum had a 52-7,210-fold (mean \pm SD, 1,350 $\pm 1,870 ; 95 \%$ CI, 458-2,250) higher QICI than B. longum and a 3-188-fold (mean \pm SD, $33 \pm 44$; 95\% CI, 12-54) higher QICI than L. lactis ssp. lactis. The present results indicated that L.plantarum had a superior QFPD-like ability to stimulate innate cytokine production by blood immune cells. Therefore, L. plantarum and B. longum were selected in all subjects for the subsequent clinical trial.

L. plantarum ingestion induces $Q F P D$-like innate cytokine responses in vivo. To investigate whether L. plantarum could reproduce in vivo the QFPD-like immunomodulatory activity observed in vitro, a single-arm, double-blind, prospective trial that included three consecutive sessions was conducted: i) A validation session using L. plantarum in the first 7 days; ii) a 7-day washout period; and iii) a control session using B. longum in the last 7 days. The peripheral blood samples that were obtained before (day 0) and after (day 8) L. plantarum ingestion and after $B$. longum ingestion (day 22) were evaluated for plasma TNF- $\alpha$, IL-1 $\beta$, IL-18, IL-8 and IL-6, as well as the QICI.

As indicated in Table I, oral intake of L. plantarum significantly increased plasma IL-1 $\beta$ [median (IQR), 0.000 (0.000-0.000) vs. 0.134 (0.092-0.292) pg/ml; $\mathrm{P}=0.0000310$ after Friedman test; $\mathrm{P}=0.00284$ after Nemenyi post hoc test] and decreased plasma IL-6 [median (IQR), 1.180 (0.812-2.130) vs. $0.495(0.425-0.775) \mathrm{pg} / \mathrm{ml} ; \mathrm{P}=0.0131$ after Friedman test; $\mathrm{P}=0.0128$ after Nemenyi post hoc test]. There were no significant differences in the plasma levels of TNF- $\alpha$, IL-18 and IL-8. The QICI value was significantly increased [mean fold change, 17-fold; median (IQR), 1,760 (680-3,550) vs. 12,300 


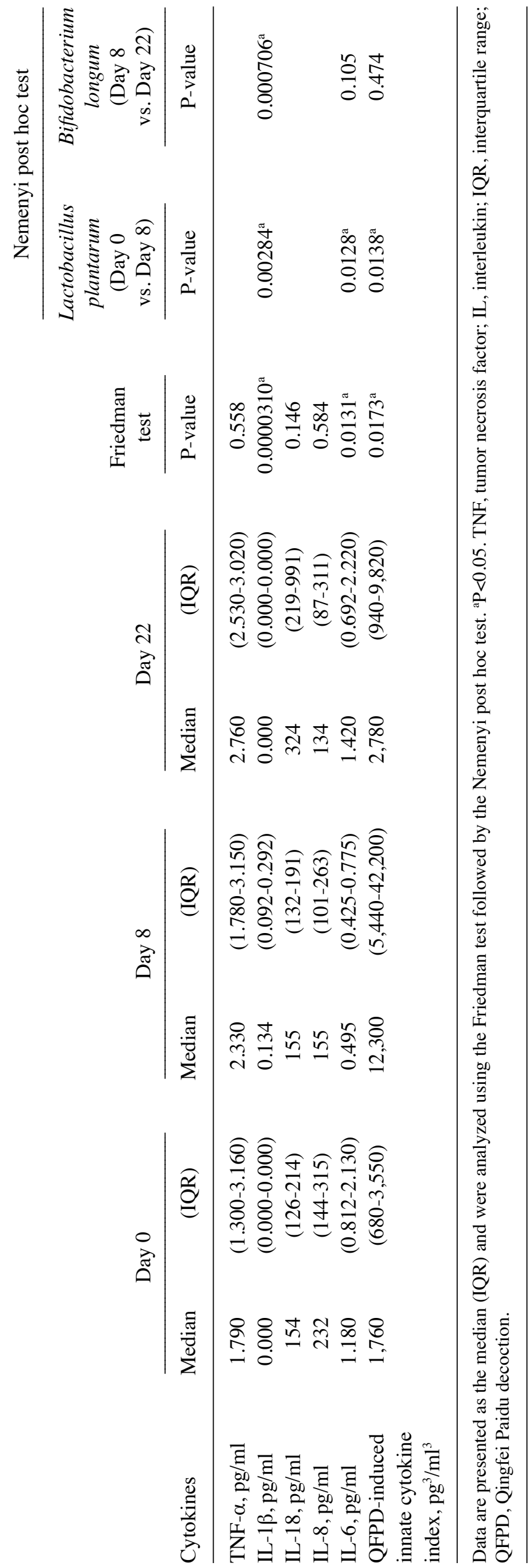


A

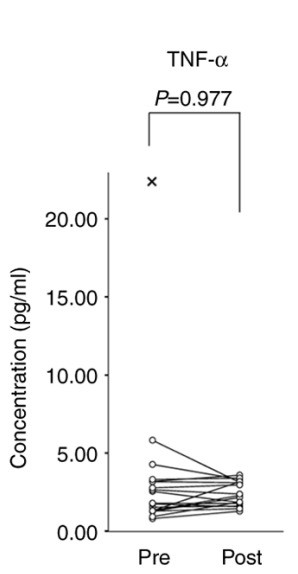

B

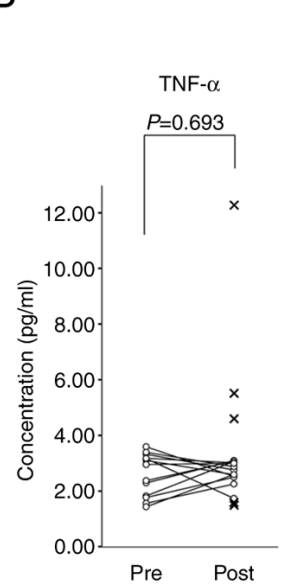

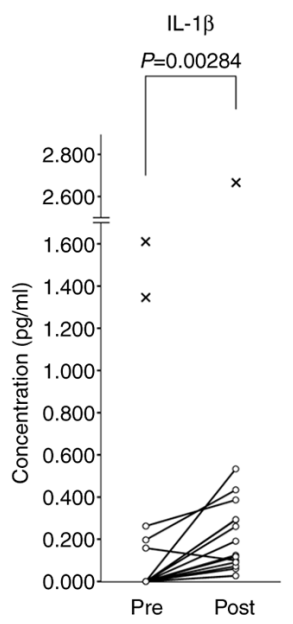
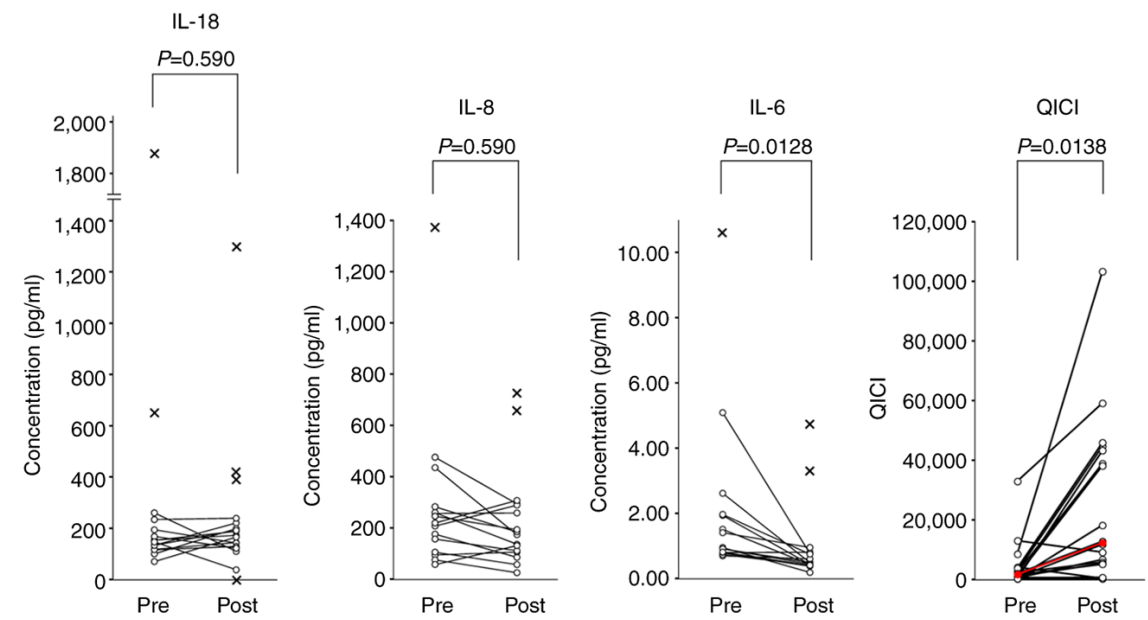

IL-1ß
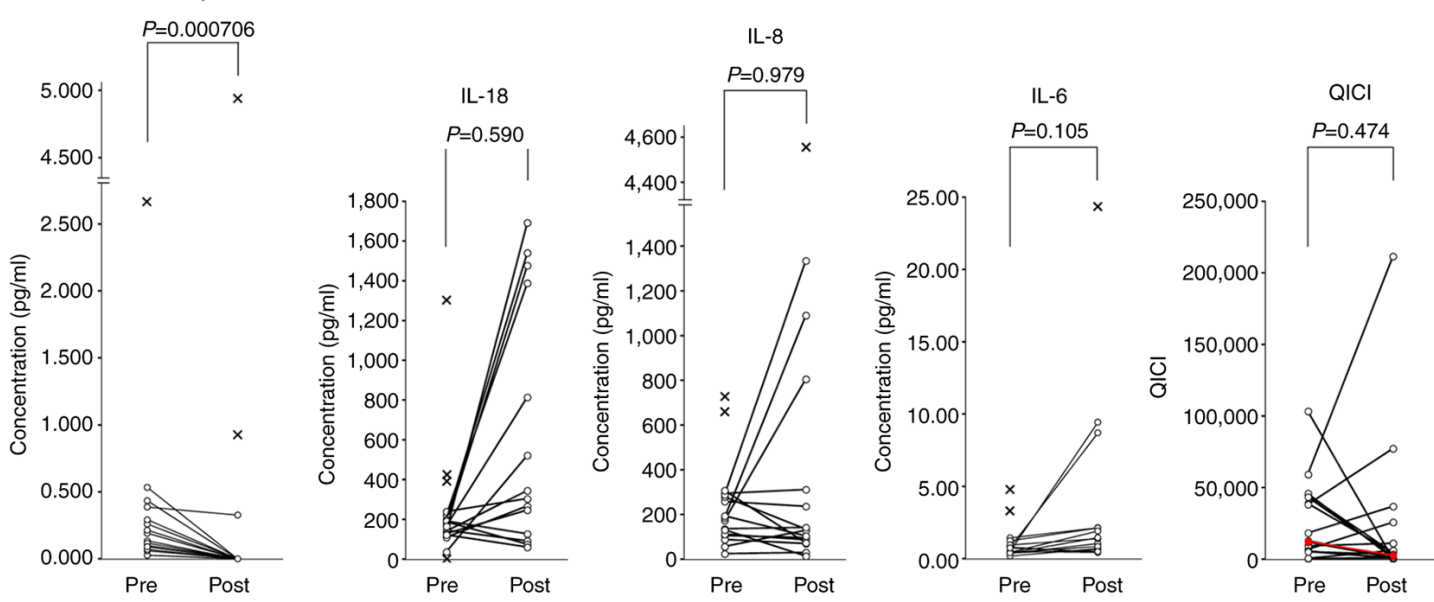

Figure 2. Changes in plasma cytokine levels and QICI values before (pre) and after (post) oral intake of (A) Lactobacillus plantarum SNK12 and (B) Bifidobacterium longum BB536. QICI was defined as follows: QICI=(TNF- $\alpha$ ) x (IL-1 $\beta$ ) x (IL-18) x (IL-8)/(IL-6), where brackets represent the plasma level of the cytokine in pg/ml. Cross marks denote outliers. Each red line represents the change of the medians. The data were statistically analyzed using the Friedman test followed by the Nemenyi post hoc test. QICI, Qingfei Paidu decoction-induced innate cytokine index.

(5,440-42,200); $\mathrm{P}=0.0173$ after Friedman test; $\mathrm{P}=0.0138$ after Nemenyi post hoc test]. The QICI values were increased in 16 of 18 subjects $(88.9 \%)$ with considerable individual differences in the fold change (1-128-fold; mean fold change, 19-fold; Fig. 2A), suggesting that there are large variations in responsiveness to $L$. plantarum among individuals.

By contrast, oral intake of B. longum induced a significant decrease in plasma IL-1 $\beta$ [median (IQR), 0.134 (0.092-0.292) vs. $0.000(0.000-0.000) \mathrm{pg} / \mathrm{ml} ; \mathrm{P}=0.0000310$ after Friedman test; $\mathrm{P}=0.000706$ after Nemenyi post hoc test]; however, the QICI value did not change significantly [mean fold change, 2-fold; median (IQR), 12,300 (5,440-42,200) vs. 2,780 (940-9,820); $\mathrm{P}=0.0173$ after Friedman test; $\mathrm{P}=0.474$ after Nemenyi post hoc test]. The QICI values increased in 8 of 18 subjects $(44.4 \%)$, but the fold changes were markedly lower (1-9-fold; mean fold change, 3-fold; Fig. 2B) than those obtained during the L. plantarum session. The present results suggested that orally administered L. plantarum induced an in vivo cytokine change similar to that induced by oral QFPD in a previous experiment (51).

L. plantarum ingestion also caused a minor but significant change the mean corpuscular hemoglobin concentration [median (IQR), 33.3 (32.4-33.9) vs. 32.6 (32.1-33.1)\%;
$\mathrm{P}=0.00456$ after Friedman test; $\mathrm{P}=0.00836$ after Nemenyi post hoc test] (Table SII). No significant changes in the hematological parameters were observed during the B. longum session (Table SII).

The post hoc two-tailed power analysis revealed that satisfactory effect sizes were obtained [0.845 (QICI in the L. plantarum session)-1.20 (IL-1 $\beta$ in the B. longum session)], as well as statistical powers [0.908 (QICI in the L. plantarum session)-0.996 (IL-1 $\beta$ in the B. longum session)] after completion of the trial (Table SIII).

Effects of L. plantarum ingestion on the innate immune cell activity. Subsequently, the present study examined whether the L. plantarum-induced cytokine changes (increase in the QICI score) led to the increased activity of innate immune cells. L. plantarum ingestion significantly enhanced the activity of NK cells, which are key effectors of antiviral innate immunity that directly attack virus-infected host cells (Table II; Fig. 3A) (77,78). By contrast, B. longum ingestion significantly promoted the phagocytic activity of neutrophils (Table II; Fig. 3B). Neither L. plantarum nor B. longum ingestion activated macrophages, as assessed by the serum neopterin levels (Table II; Fig. 3C). The present results further supported the 

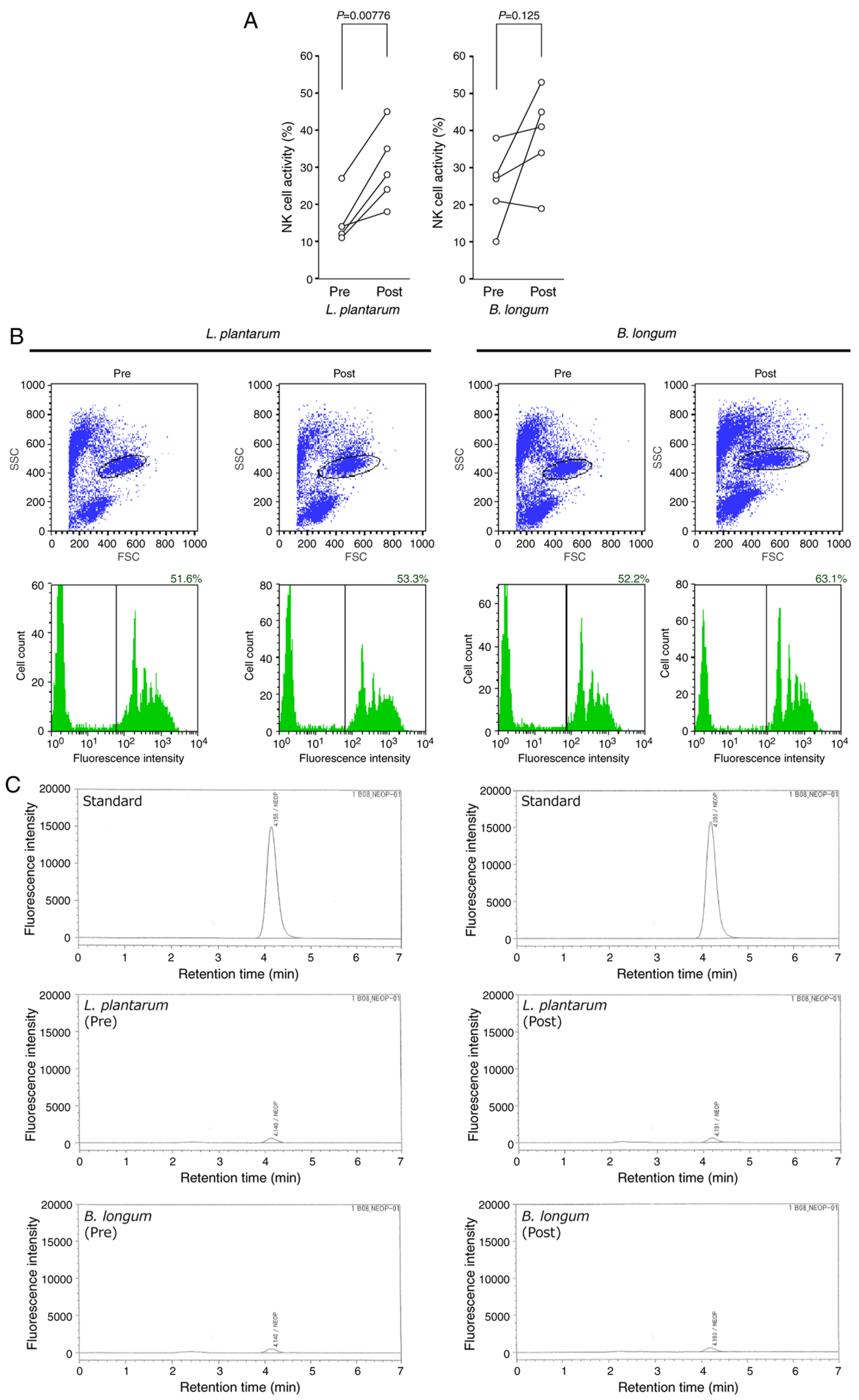

Figure 3. Effects of L. plantarum or B. longum ingestion on the innate immune cell activity. (A) NK cell activity before (pre) and after (post) the L.plantarum or B. longum ingestion. (B) Phagocytic activity of neutrophils. Representative flow cytometry plots are presented in the upper panels. The vertical and horizontal axes are SSC and FSC, respectively. Areas surrounded by black lines represent granulocyte populations characterized as medium FSC/high SSC (granulocyte gating). Histograms of fluorescence intensities of the granulocytes separated by the granulocyte gating are presented in the lower panels. The vertical and horizontal axes demonstrate cell count and fluorescence intensity, respectively. A black vertical line in each histogram indicates the threshold of fluorescence-positive granulocytes (granulocytes that phagocytosed the fluorescent microbeads). The phagocytic activity was calculated as the ratio of fluorescence-positive granulocytes to the total count of granulocytes and presented in the upper right corner of each histogram. (C) Macrophage activity. The serum levels of neopterin, an activation marker of monocytes and macrophages, were determined using reverse-phase high-performance liquid chromatography. Representative chromatograms are presented. The vertical and horizontal axes show the intensity of native fluorescence of neopterin and retention time, respectively. NK, natural killer; L. plantarum, Lactobacillus plantarum; B. longum, Bifidobacterium longum; FSC, forward scatter; SSC, side scatter. 
immunological benefits of $L$. plantarum and B. longum against viral infection.

\section{Discussion}

A large body of evidence has suggested that L. plantarum strengthens several aspects of the host defense mechanism against the infection by respiratory viruses, particularly seasonal and highly pathogenic influenza viruses. For example, oral administration of L. plantarum in mice significantly suppressed viral replication in the lungs and reduced airway inflammation, thereby increasing survival rates (33-39). The underlying immunological effects are known to be diverse, including stimulation of type I IFN production $(37,39)$, enhancement of NK cell activity $(36,39)$, promotion of T helper type 1 cell-mediated immune responses $(33,34,39)$ and activation of IgA-dependent mucosal immunity in the small intestine and lung $(34,35)$. Similarly, randomized controlled trials have demonstrated that oral intake of $L$. plantarum reduced the risk of upper/lower respiratory tract infection and alleviated the respiratory symptoms of infected patients $(30,79)$. The protective efficacy is associated with enhancement of the phagocytic activity of granulocytes, reduction of the plasma proinflammatory cytokines IFN $-\gamma$ and TNF- $\alpha$, elevation of the anti-inflammatory cytokines IL- 4 and IL-10, activation of $\mathrm{CD} 8^{+} \mathrm{T}$ cells and induction of the specific secretory IgA neutralizing antibodies in the bronchoalveolar lavage fluid (BALF) and sera $(30,31)$.

In line with the wide variety of immunomodulatory abilities of L.plantarum, the SNK12 strain was indicated to exhibit protective effects against influenza A virus subtype H1N1 $(57,58)$. The SNK12 strain has been isolated from traditional non-salted pickles of autochthonous red turnip that have been produced in the Kiso area of Nagano prefecture in Japan for $>400$ years (80). Recent animal studies demonstrated that oral administration of $L$. plantarum strain SNK12 to mice before influenza viral challenge suppressed the viral load in the BALF and lung, induced a higher titer of neutralizing antibodies in the BALF and sera and higher levels of specific IgA in BALF and feces compared with control mice and mice treated with the anti-influenza drug oseltamivir $(57,58)$.

The present study revealed that $L$. plantarum SNK12 could also upregulate a subset of proinflammatory cytokines, as assessed both in vitro and in humans. This immunomodulatory effect is likely contradictory to its potential for clinical benefits against the influenza virus, since the patients present with a broad range of inflammatory symptoms. However, it is notable that acute, low-grade inflammation is a physiological basis for early stages of host defense mechanisms and has been demonstrated to serve a protective role against viral infection. Kechaou et al (32) demonstrated that a proinflammatory L. plantarum strain with superior ability to stimulate the production of IL- 8 and IL-12 markedly inhibited viral proliferation in the lung and alleviated clinical symptoms in mice when orally administered before or after influenza virus challenge. Furthermore, Park et al (33) revealed that ingestion by mice of a probiotic L. plantarum strain conferred protection against influenza virus by elevating both IL-12 and IFN- $\gamma$ levels in the BALF and inducing low-grade inflammation. 
QFPD consists of 21 traditional Chinese herbs optimized specifically against the symptoms of COVID-19 (43). QFPD has demonstrated satisfactory therapeutic benefits in patients with mild-to-severe disease in clinical trials in China (46-50) and has been recommended officially for the treatment of COVID-19 (43). Our recent clinical study indicated that oral QFPD upregulated the blood levels of TNF- $\alpha$, IL-1 $\beta$, IL-18 and IL-8, which are key mediators of innate immune responses to viral infection (51). TNF- $\alpha$, IL-1 $\beta$ and IL-18 are induced directly by toll like receptor (TLR)7/TLR8 and NLR family pyrin domain containing 3 (NLRP3), foreign single-stranded RNA (ssRNA) sensors in dendritic cells and macrophages (81-83). These 'immediate-early' cytokines initiate and coordinate a broad spectrum of downstream antiviral immune cascades (81-83). Notably, recent metagenomics studies demonstrated that the TLR7/8- and NLRP3/inflammasome-mediated inflammatory pathways are strongly suppressed in the upper airway of patients with COVID-19 and those non-responsive to SARS-CoV-2 infection early in the course of the disease $(84,85)$. These findings highlight the importance of the active TLR7/8- and NLRP3-driven inflammatory pathways in the early stages of anti-SARS-CoV-2 immunity. We hypothesized that QFPD, which mimics the blood cytokine environment produced by TLR7/8- and NLRP3-driven early innate immune responses to ssRNA viruses, may be effective in preventing SARS-CoV-2 infection (51). The present study suggested that L. plantarum, which can stimulate innate cytokine changes similar to those induced by oral QFPD, may also potentially provide a protective benefit against COVID-19.

IL-6 serves key roles in complex immune dysregulation and systemic hyperinflammation, which are hallmarks of severe COVID-19, and IL-6 blood level has been associated with COVID-19 severity and mortality (54-56). The production of IL- 6 and TNF- $\alpha$ is stimulated directly by common TLR7/8-driven intracellular signaling in response to ssRNA viruses (81-83). However, L. plantarum ingestion significantly increased the plasma level of TNF- $\alpha$, whereas it downregulated IL-6 plasma level in the present trial. Although the mechanism of this opposite effect remains unknown, the ability of L. plantarum to reduce blood IL-6 may be indicative of its prophylactic administration to uninfected individuals.

Recent transcriptomic studies have demonstrated that exhausted NK cell responses determine severity and fatality of COVID-19. Liu et al (86) have identified IL-15-mediated attenuated inflammation in NK cells as being primarily associated with COVID-19 severity. A study by Sahoo et al (87) has also highlighted that IL15-mediated NK cell exhaustion, senescence and apoptosis are important determinants for severe/fatal COVID-19. L. plantarum-induced activation of NK cells may therefore be efficacious as an adjunctive therapy to improve NK cell exhaustion and dysfunction in severe or fatal COVID-19.

The main limitations of the current study are the small number of participants, the selection of uninfected individuals as subjects and a female-biased gender ratio in the subjects. Further clinical studies with larger cohorts are required to confirm the conclusions and determine generalizability. The uninfected subjects employed were healthy, in order to examine the feasibility of prophylactic, daily use of L. plantarum. As a result, no chest CT images of the subjects were obtained. Additional studies are essential to clarify whether L. plantarum can induce the similar cytokine changes and improve chest CT findings in patients with COVID-19. Further studies are also required to identify probiotic strains with the ability to strengthen innate immunity by inducing moderate physiological inflammation. In addition, in the control session using B. longum (day 15-21), blood samples were obtained at day 8 as baseline, not at day 14 . Since the plasma IL-1 $\beta$ and IL- 6 levels had been up- or down-regulated by L. plantarum by day 8 , it is not possible to exclude the possibility that the IL-1 $\beta$ and IL-6 levels were spontaneously restored to the day 0 levels during days 8-22 without the effects of B. longum. Similarly, there was a significant increase in the QICI in the L. plantarum session (Table I, comparison between day 0 and day 8), whereas no significant change in the QICI was observed in the B. longum session (comparison between day 8 and day 22). $B$. longum sustained the QICI score that had been upregulated by L. plantarum. Therefore, it cannot be excluded either that B. longum also had positive effects on the QICI score in vivo.

Considering the recent emergence of novel SARS-CoV-2 variants with relevant mutations that potentially affect the efficacy of vaccines and therapeutic antibodies, there is an increasing need to prepare diverse prophylactic and therapeutic options against COVID-19. The present study indicated that L. plantarum exhibited a superior ability to mimic inflammatory innate cytokine responses essential for early stages of host defense mechanism against viral infection. Daily consumption of probiotic L. plantarum strains may be a reasonably safe, cost-effective and viable option to protect uninfected individuals against SARS-CoV-2 infection during the pandemic.

\section{Acknowledgements}

Not applicable.

\section{Funding}

No funding was received.

\section{Availability of data and materials}

The datasets used and/or analyzed during the current study are available from the corresponding author on reasonable request.

\section{Authors' contributions}

YK, YN, TE, TA and TN conceived the study. YK, YN, TE, TA and TN developed the methodology. TN performed formal analysis. YK, KA, KY and TE performed/interpreted the experiments. YK, KA, KY and TE provided resources. YK and TE curated data. TN wrote the original draft. YK, YN, KA, KY, TE and TA reviewed and edited the manuscript. TN was involved in visualization. YK, YN, TA and TN supervised the study. YK, KA and TE were involved in project administration. YK, TE and TN confirm the authenticity of all the raw data. All authors have read and approved the final manuscript.

\section{Ethics approval and consent to participate}

The present study was carried out in accordance with The Code of Ethics of the World Medical Association (The Declaration of 
Helsinki). All procedures were reviewed and approved by the Ethics Committees of Takanawa Clinic (approval nos. 2016-3, 20 December 2016 and 2020-2, 7 May 2020; Tokyo, Japan). A signed informed consent form was obtained from each participant prior to inclusion in the present study.

\section{Patient consent for publication}

Not applicable.

\section{Competing interests}

YK, KA, KY and TE are employees of Takanawa Clinic. TA and TN serve as research advisors to Takanawa Clinic and receive advisory fees.

\section{References}

1. Lukassen S, Chua RL, Trefzer T, Kahn NC, Schneider MA Muley T, Winter H, Meister M, Veith C, Boots AW, et al: SARS-CoV-2 receptor ACE2 and TMPRSS2 are primarily expressed in bronchial transient secretory cells. EMBO J 39: e105114, 2020

2. Sungnak W, Huang N, Bécavin C, Berg M, Queen R, Litvinukova M, Talavera-López C, Maatz H, Reichart D, Sampaziotis F, et al: SARS-CoV-2 entry factors are highly expressed in nasal epithelial cells together with innate immune genes. Nat Med 26: 681-687, 2020.

3. Ziegler CGK, Allon SJ, Nyquist SK, Mbano IM, Miao VN, Tzouanas CN, Cao Y, Yousif AS, Bals J, Hauser BM, et al: SARS-CoV-2 receptor ACE2 is an interferon-stimulated gene in human airway epithelial cells and is detected in specific cell subsets across tissues. Cell 181: 1016-1035.e19, 2020.

4. Lee JJ, Kopetz S, Vilar E, Shen JP, Chen K and Maitra A: Relative abundance of SARS-CoV-2 entry genes in the enterocytes of the lower gastrointestinal tract. Genes (Basel) 11: 645, 2020.

5. Zang R, Gomez Castro MF, McCune BT, Zeng Q, Rothlauf PW, Sonnek NM, Liu Z, Brulois KF, Wang X, Greenberg HB, et al: TMPRSS 2 and TMPRSS4 promote SARS-CoV-2 infection of human small intestinal enterocytes. Sci Immunol 5: eabc3582, 2020.

6. Lamers MM, Beumer J, van der Vaart J, Knoops K, Puschhof J, Breugem TI, Ravelli RBG, Paul van Schayck J, Mykytyn AZ, Duimel HQ, et al: SARS-CoV-2 productively infects human gut enterocytes. Science 369: 50-54, 2020.

7. Xiao F, Tang M, Zheng X, Liu Y, Li X and Shan H: Evidence for gastrointestinal infection of SARS-CoV-2. Gastroenterology 158 : 1831-1833.e3, 2020.

8. Zhou J, Li C, Liu X, Chiu MC, Zhao X, Wang D, Wei Y, Lee A, Zhang $\mathrm{AJ}$, Chu $\mathrm{H}$, et al: Infection of bat and human intestinal organoids by SARS-CoV-2. Nat Med 26: 1077-1083, 2020.

9. Chen Y, Chen L, Deng Q, Zhang G, Wu K, Ni L, Yang Y, Liu B, Wang W, Wei C, et al: The presence of SARS-CoV-2 RNA in the feces of COVID-19 patients. J Med Virol 92: 833-840, 2020.

10. Kipkorir V, Cheruiyot I, Ngure B, Misiani M and Munguti J: Prolonged SARS-CoV-2 RNA detection in anal/rectal swabs and stool specimens in COVID-19 patients after negative conversion in nasopharyngeal RT-PCR test. J Med Virol 92: 2328-2331, 2020.

11. Wu Y, Guo C, Tang L, Hong Z, Zhou J, Dong X, Yin H, Xiao Q, Tang Y, Qu X, et al: Prolonged presence of SARS-CoV-2 viral RNA in faecal samples. Lancet Gastroenterol Hepatol 5: 434-435, 2020.

12. Gu J, Han B and Wang J: COVID-19: Gastrointestinal manifestations and potential fecal-oral transmission. Gastroenterology 158: 1518-1519, 2020.

13. Wong SH, Lui RN and Sung JJ: Covid-19 and the digestive system. J Gastroenterol Hepatol 35: 744-748, 2020.

14. Yang $\mathrm{L}$ and $\mathrm{Tu} \mathrm{L}$ : Implications of gastrointestinal manifestations of COVID-19. Lancet Gastroenterol Hepatol 5: 629-630, 2020.

15. Budden KF, Gellatly SL, Wood DL, Cooper MA, Morrison M, Hugenholtz $\mathrm{P}$ and Hansbro PM: Emerging pathogenic links between microbiota and the gut-lung axis. Nat Rev Microbiol 15: 55-63, 2017.
16. Dumas A, Bernard L, Poquet Y, Lugo-Villarino G and Neyrolles O: The role of the lung microbiota and the gut-lung axis in respiratory infectious diseases. Cell Microbiol 20: e12966, 2018

17. Zhang D, Li S, Wang N, Tan HY, Zhang Z and Feng Y: The cross-talk between gut microbiota and lungs in common lung diseases. Front Microbiol 11: 301, 2020.

18. Gu S, Chen Y, Wu Z, Chen Y, Gao H, Lv L, Guo F, Zhang X, Luo R, Huang $\mathrm{C}$, et al: Alterations of the gut microbiota in patients with coronavirus disease 2019 or H1N1 influenza. Clin Infect Dis 71: 2669-2678, 2020

19. Gou W, Fu Y, Yue L, Chen GD, Cai X, Shuai M, Xu F, Yi X, Chen H, Zhu Y, et al: Gut microbiota may underlie the predisposition of healthy individuals to COVID-19. J Genet Genomics 48: 792-802, 2021.

20. Zuo T, Liu Q, Zhang F, Lui GC, Tso EY, Yeoh YK, Chen Z, Boon SS, Chan FK, Chan PK, et al: Depicting SARS-CoV-2 faecal viral activity in association with gut microbiota composition in patients with COVID-19. Gut 70: 276-284, 2021.

21. Zuo T, Zhang F, Lui GCY, Yeoh YK, Li AYL, Zhan H, Wan Y, Chung ACK, Cheung CP, Chen N, et al: Alterations in gut microbiota of patients with COVID-19 during time of hospitalization. Gastroenterology 159: 944-955.e8, 2020.

22. Lehtoranta L, Pitkaranta A and Korpela R: Probiotics in respiratory virus infections. Eur J Clin Microbiol Infect Dis 33: 1289-1302, 2014

23. Lei WT, Shih PC, Liu SJ, Lin CY and Yeh TL: Effect of probiotics and prebiotics on immune response to influenza vaccination in adults: A systematic review and meta-analysis of randomized controlled trials. Nutrients 9: 1175, 2017.

24. Luoto R, Ruuskanen O, Waris M, Kalliomaki M, Salminen S and Isolauri E: Prebiotic and probiotic supplementation prevents rhinovirus infections in preterminfants: Arandomized,placebo-controlled trial. J Allergy Clin Immunol 133: 405-413, 2014.

25. Turner RB, Woodfolk JA, Borish L, Steinke JW, Patrie JT, Muehling LM, Lahtinen S and Lehtinen MJ: Effect of probiotic on innate inflammatory response and viral shedding in experimental rhinovirus infection-a randomised controlled trial. Benef Microbes 8: 207-215, 2017.

26. Yeh TL, Shih PC, Liu SJ, Lin CH, Liu JM, Lei WT and Lin CY: The influence of prebiotic or probiotic supplementation on antibody titers after influenza vaccination: A systematic review and meta-analysis of randomized controlled trials. Drug Des Devel Ther 12: 217-230, 2018.

27. Blanco-Melo D, Nilsson-Payant BE, Liu WC, Uhl S, Hoagland D, Møller R, Jordan TX, Oishi K, Panis M, Sachs D, et al: Imbalanced host response to SARS-CoV-2 drives development of COVID-19. Cell 181: 1036-1045.e9, 2020.

28. Cao X: COVID-19: Immunopathology and its implications for therapy. Nat Rev Immunol 20: 269-270, 2020.

29. Giamarellos-Bourboulis EJ, Netea MG, Rovina N, Akinosoglou K, Antoniadou A, Antonakos N, Damoraki G, Gkavogianni T, Adami ME, Katsaounou P, et al: Complex immune dysregulation in COVID-19 patients with severe respiratory failure. Cell Host Microbe 27: 992-1000.e3, 2020

30. Chong HX, Yusoff NAA, Hor YY, Lew LC, Jaafar MH, Choi SB, Yusoff MSB, Wahid N, Abdullah MFIL, Zakaria N, et al: Lactobacillus plantarum DR7 improved upper respiratory tract infections via enhancing immune and inflammatory parameters: A randomized, double-blind, placebo-controlled study. J Dairy Sci 102: 4783-4797, 2019.

31. Rask C, Adlerberth I, Berggren A, Ahren IL and Wold AE: Differential effect on cell-mediated immunity in human volunteers after intake of different lactobacilli. Clin Exp Immunol 172: 321-332, 2013.

32. Kechaou N, Chain F, Gratadoux JJ, Blugeon S, Bertho N, Chevalier C, Le Goffic R, Courau S, Molimard P, Chatel JM, et al: Identification of one novel candidate probiotic Lactobacillus plantarum strain active against influenza virus infection in mice by a large-scale screening. Appl Environ Microbiol 79: 1491-1499, 2013.

33. Park MK, Ngo V, Kwon YM, Lee YT, Yoo S, Cho YH, Hong SM, Hwang HS, Ko EJ, Jung YJ, et al: Lactobacillus plantarum DK119 as a probiotic confers protection against influenza virus by modulating innate immunity. PLoS One 8: e75368, 2013.

34. Kawashima T, Hayashi K, Kosaka A, Kawashima M, Igarashi T, Tsutsui H, Tsuji NM, Nishimura I, Hayashi T and Obata A: Lactobacillus plantarum strain YU from fermented foods activates Th1 and protective immune responses. Int Immunopharmacol 11: 2017-2024, 2011. 
35. Kikuchi Y, Kunitoh-Asari A, Hayakawa K, Imai S, Kasuya K, Abe K, Adachi Y, Fukudome S, Takahashi Y and Hachimura S: Oral administration of Lactobacillus plantarum strain AYA enhances IgA secretion and provides survival protection against influenza virus infection in mice. PLoS One 9: e86416, 2014.

36. Kim DH, Chung WC, Chun SH, Han JH, Song MJ and Lee KW: Enhancing the natural killer cell activity and anti-influenza effect of heat-treated Lactobacillus plantarum $\mathrm{nF}$-fortified yogurt in mice. J Dairy Sci 101: 10675-10684, 2018.

37. Maeda N, Nakamura R, Hirose Y, Murosaki S, Yamamoto Y, Kase T and Yoshikai Y: Oral administration of heat-killed Lactobacillus plantarum L-137 enhances protection against influenza virus infection by stimulation of type I interferon production in mice. Int Immunopharmacol 9: 1122-1125, 2009.

38. Park S, Kim JI, Bae JY, Yoo K, Kim H, Kim IH, Park MS and Lee I: Effects of heat-killed Lactobacillus plantarum against influenza viruses in mice. J Microbiol 56: 145-149, 2018.

39. Takeda S, Takeshita M, Kikuchi Y, Dashnyam B, Kawahara S, Yoshida H, Watanabe W, Muguruma M and Kurokawa M: Efficacy of oral administration of heat-killed probiotics from Mongolian dairy products against influenza infection in mice: Alleviation of influenza infection by its immunomodulatory activity through intestinal immunity. Int Immunopharmacol 11: 1976-1983, 2011.

40. Kawahara T, Takahashi T, Oishi K, Tanaka H, Masuda M, Takahashi S, Takano M, Kawakami T, Fukushima K, Kanazawa $\mathrm{H}$ and Suzuki T: Consecutive oral administration of Bifidobacterium longum MM-2 improves the defense system against influenza virus infection by enhancing natural killer cell activity in a murine model. Microbiol Immunol 59: 1-12, 2015.

41. Namba K, Hatano M, Yaeshima T, Takase M and Suzuki K Effects of Bifidobacterium longum BB536 administration on influenza infection, influenza vaccine antibody titer, and cell-mediated immunity in the elderly. Biosci Biotechnol Biochem 74: 939-945, 2010.

42. Sugimura T, Takahashi H, Jounai K, Ohshio K, Kanayama M, Tazumi K, Tanihata Y, Miura Y, Fujiwara D and Yamamoto N: Effects of oral intake of plasmacytoid dendritic cells-stimulative lactic acid bacterial strain on pathogenesis of influenza-like illness and immunological response to influenza virus. $\mathrm{Br}$ J Nutr 114: 727-733, 2015

43. Shi HY, Zhu X, Li WL, Mak JWY, Wong SH, Zhu ST, Guo SL, Chan FKL, Zhang ST and Ng SC: Modulation of gut microbiota protects against viral respiratory tract infections: A systematic review of animal and clinical studies. Eur J Nutr: Apr 14, 2021 (Epub ahead of print).

44. Wang F, Pan B, Xu S, Xu Z, Zhang T, Zhang Q, Bao Y, Wang Y, Zhang J, Xu C and Xue X: A meta-analysis reveals the effectiveness of probiotics and prebiotics against respiratory viral infection. Biosci Rep 41: BSR20203638, 2021

45. Wei PF, (ed). Diagnosis and Treatment Protocol for Novel Coronavirus Pneumonia (Trial Version 7). Chin Med J (Engl) 133: 1087-1095, 2020.

46. Cao P, Wu S, Wu T, Deng Y, Zhang Q, Wang K and Zhang Y: The important role of polysaccharides from a traditional Chinese medicine-Lung cleansing and detoxifying decoction against the COVID-19 pandemic. Carbohydr Polym 240: $116346,2020$.

47. Shi N, Liu B, Liang N, Ma Y, Ge Y, Yi H, Wo H, Gu H, Kuang Y, Tang S, et al: Association between early treatment with Qingfei Paidu decoction and favorable clinical outcomes in patients with COVID-19: A retrospective multicenter cohort study. Pharmacol Res 161: 105290, 2020.

48. Zhao ZH, Zhou Y, Li WH, Huang QS, Tang ZH and Li H: Analysis of traditional Chinese medicine diagnosis and treatment strategies for COVID-19 based on 'The Diagnosis and Treatment Program for Coronavirus Disease-2019' from Chinese Authority. Am J Chin Med 48: 1035-1049, 2020

49. Zhong LLD, Lam WC, Yang W, Chan KW, Sze SCW, Miao J, Yung KKL, Bian Z and Wong VT: Potential targets for treatment of coronavirus disease 2019 (COVID-19): A review of Qing-Fei-Pai-Du-Tang and its major herbs. Am J Chin Med 48: 1051-1071, 2020.

50. Xin S, Cheng X, Zhu B, Liao X, Yang F, Song L, Shi Y, Guan X, Su R, Wang J, et al: Clinical retrospective study on the efficacy of Qingfei Paidu decoction combined with Western medicine for COVID-19 treatment. Biomed Pharmacother 129: 110500, 2020 .
51. Kageyama Y, Aida K, Kawauchi K, Morimoto M, Ebisui T, Akiyama T and Nakamura T: Qingfei Paidu decoction, a Chinese herbal medicine against COVID-19, elevates the blood levels of pro-inflammatory cytokines: An open-label, single-arm pilot study. World Acad Sci J 3: 25, 2021.

52. Popkin BM, Du S, Green WD, Beck MA, Algaith T, Herbst CH, Alsukait RF, Alluhidan M, Alazemi N and Shekar M: Individuals with obesity and COVID-19: A global perspective on the epidemiology and biological relationships. Obes Rev 21: e13128, 2020.

53. Kompaniyets L, Goodman AB, Belay B, Freedman DS Sucosky MS, Lange SJ, Gundlapalli AV, Boehmer TK and Blanck HM: Body mass index and risk for COVID-19-related hospitalization, intensive care unit admission, invasive mechanical ventilation, and Death-United States, march-december 2020. MMWR Morb Mortal Wkly Rep 70: 355-361, 2021.

54. Elshazli RM, Toraih EA, Elgaml A, El-Mowafy M, El-Mesery M, Amin MN, Hussein MH, Killackey MT, Fawzy MS and Kandil E: Diagnostic and prognostic value of hematological and immunological markers in COVID-19 infection: A meta-analysis of 6320 patients. PLoS One 15: e0238160, 2020.

55. Mesas AE, Cavero-Redondo I, Álvarez-Bueno C, Sarriá Cabrera MA, Maffei de Andrade S, Sequí-Dominguez I and Martínez-Vizcaíno V: Predictors of in-hospital COVID-19 mortality: A comprehensive systematic review and meta-analysis exploring differences by age, sex and health conditions. PLoS One 15: e0241742, 2020.

56. Zhang X, Tan Y, Ling Y, Lu G, Liu F, Yi Z, Jia X, Wu M, Shi B, $\mathrm{Xu}$ S, et al: Viral and host factors related to the clinical outcome of COVID-19. Nature 583: 437-440, 2020.

57. Okumura A, Watanabe T, Hayashi K and Yoshida H: Oral administration of distribution-processed Lactobacillus plantarum strain SNK12 protects against influenza virus infection. Jpn Pharmacol Ther 47: 1607-1612, 2019.

58. Watanabe T, Hayashi K, Kan T, Ohwaki M and Kawahara T: Anti-influenza virus effects of Enterococcus faecalis $\mathrm{KH} 2$ and Lactobacillus plantarum SNK12 RNA. Biosci Microbiota Food Health 40: 43-49, 2021.

59. Xiao JZ, Kondo S, Yanagisawa N, Miyaji K, Enomoto K, Sakoda T, Iwatsuki K and Enomoto T: Clinical efficacy of probiotic Bifidobacterium longum for the treatment of symptoms of Japanese cedar pollen allergy in subjects evaluated in an environmental exposure unit. Allergol Int 56: 67-75, 2007.

60. Xiao JZ, Kondo S, Yanagisawa N, Takahashi N, Odamaki T, Iwabuchi N, Iwatsuki K, Kokubo S, Togashi H, Enomoto K and Enomoto T: Effect of probiotic Bifidobacterium longum BB536 [corrected] in relieving clinical symptoms and modulating plasma cytokine levels of Japanese cedar pollinosis during the pollen season. A randomized double-blind, placebo-controlled trial. J Investig Allergol Clin Immunol 16: 86-93, 2006.

61. Iwabuchi N, Xiao JZ, Yaeshima T and Iwatsuki K: Oral administration of Bifidobacterium longum ameliorates influenza virus infection in mice. Biol Pharm Bull 34: 1352-1355, 2011.

62. Lau AS, Yanagisawa N, Hor YY, Lew LC, Ong JS Chuah LO, Lee YY, Choi SB, Rashid F, Wahid N, et al: Bifidobacterium longum BB536 alleviated upper respiratory illnesses and modulated gut microbiota profiles in Malaysian pre-school children. Benef Microbes 9: 61-70, 2018.

63. Odamaki T, Sugahara H, Yonezawa S, Yaeshima T, Iwatsuki K, Tanabe S, Tominaga T, Togashi H, Benno Y and Xiao JZ: Effect of the oral intake of yogurt containing Bifidobacterium longum BB536 on the cell numbers of enterotoxigenic Bacteroides fragilis in microbiota. Anaerobe 18: 14-18, 2012.

64. Odamaki T, Xiao JZ, Iwabuchi N, Sakamoto M, Takahashi N, Kondo S, Miyaji K, Iwatsuki K, Togashi H, Enomoto T and Benno Y: Influence of Bifidobacterium longum BB536 intake on faecal microbiota in individuals with Japanese cedar pollinosis during the pollen season. J Med Microbiol 56: 1301-1308, 2007.

65. Holvoet $S$, Zuercher AW, Julien-Javaux F, Perrot $M$ and Mercenier A: Characterization of candidate anti-allergic probiotic strains in a model of th2-skewed human peripheral blood mononuclear cells. Int Arch Allergy Immunol 161: 142-154, 2013.

66. Medina M, Izquierdo E, Ennahar S and Sanz Y: Differential immunomodulatory properties of Bifidobacterium logum strains: Relevance to probiotic selection and clinical applications. Clin Exp Immunol 150: 531-538, 2007.

67. Niers LE, Timmerman HM, Rijkers GT, van Bleek GM, van Uden NO, Knol EF, Kapsenberg ML, Kimpen JL and Hoekstra MO: Identification of strong interleukin-10 inducing lactic acid bacteria which down-regulate $\mathrm{T}$ helper type 2 cytokines. Clin Exp Allergy 35: 1481-1489, 2005. 
68. Hoffmann G, Wirleitner B and Fuchs D: Potential role of immune system activation-associated production of neopterin derivatives in humans. Inflamm Res 52: 313-321, 2003.

69. Gieseg SP, Baxter-Parker G and Lindsay A: Neopterin, inflammation, and Oxidative Stress: What could we be missing? Antioxidants (Basel) 7: 80, 2018.

70. Hausen A, Fuchs D, König K and Wachter H: Determination of neopterine in human urine by reversed-phase high-performance liquid chromatography. J Chromatogr 227: 61-70, 1982.

71. Gleiss A, Sanchez-Cabo F, Perco P, Tong D and Heinze G: Adaptive trimmed t-statistics for identifying predominantly high expression in a microarray experiment. Stat Med 30: 52-61, 2011

72. Krzywinski $\mathrm{M}$ and Altman N: Visualizing samples with box plots. Nat Methods 11: 119-120, 2014.

73. Domthong U, Parikh CR, Kimmel PL and Chinchilli VM; Assessment, Serial Evaluation, and Subsequent Sequelae of Acute Kidney Injury Consortium: Assessing the agreement of biomarker data in the presence of left-censoring. BMC Nephrol 15: 144, 2014.

74. Yu X, Lakerveld AJ, Imholz S, Hendriks M, Ten Brink SCA Mulder HL, de Haan K, Schepp RM, Luytjes W, de Jong MD, et al: Antibody and local cytokine response to respiratory syncytial virus infection in community-dwelling older adults. mSphere 5: e00577-20, 2020.

75. Kanda Y: Investigation of the freely available easy-to-use software 'EZR' for medical statistics. Bone Marrow Transplant 48: 452-458, 2013.

76. Faul F, Erdfelder E, Lang AG and Buchner A: G*Power 3: A flexible statistical power analysis program for the social, behavioral and biomedical sciences. Behav Res Methods 39: 175-191, 2007.

77. Waggoner SN, Reighard SD, Gyurova IE, Cranert SA, Mahl SE Karmele EP, McNally JP, Moran MT, Brooks TR, Yaqoob F, et al: Roles of natural killer cells in antiviral immunity. Curr Opin Virol 16: 15-23, 2016.

78. Björkström NK, Strunz B and Ljunggren HG: Natural killer cells in antiviral immunity. Nat Rev Immunol: Jun 11, 2021 (Epub ahead of print).

79. Berggren A, Lazou Ahren I, Larsson N and Onning G: Randomised, double-blind and placebo-controlled study using new probiotic lactobacilli for strengthening the body immune defence against viral infections. Eur J Nutr 50: 203-210, 2011.
80. International Home Medical (IHM): Plant-origin nano-particled (Pro)-Biogenics immunophilus SNK. Plant-origin nano-sized lactic acid bacterium SNK ${ }^{\circledR}$. IHM Inc., Tolyo, 2021. https://www. ihmg.jp/nyusan_snk_en/. Accessed October 14, 2021.

81. Chen N, Xia P, Li S, Zhang T, Wang TT and Zhu J: RNA sensors of the innate immune system and their detection of pathogens. IUBMB Life 69: 297-304, 2017.

82. Moreno-Eutimio MA, Lopez-Macias C and Pastelin-Palacios R: Bioinformatic analysis and identification of single-stranded RNA sequences recognized by TLR7/8 in the SARS-CoV-2, SARS-CoV, and MERS-CoV genomes. Microbes Infect 22: 226-229, 2020

83. Slaats J, Ten Oever J, van de Veerdonk FL and Netea MG: IL-1//IL-6/CRP and IL-18/ferritin: Distinct inflammatory programs in infections. PLoS Pathog 12: e1005973, 2016.

84. Mick E, Kamm J, Pisco AO, Ratnasiri K, Babik JM, Castañeda G, DeRisi JL, Detweiler AM, Hao SL, Kangelaris KN, et al: Upper airway gene expression reveals suppressed immune responses to SARS-CoV-2 compared with other respiratory viruses. Nat Commun 11: 5854, 2020.

85. van der Made CI, Simons A, Schuurs-Hoeijmakers J, van den Heuvel G, Mantere T, Kersten S, van Deuren RC, Steehouwer M, van Reijmersdal SV, Jaeger M, et al: Presence of genetic variants among young men with severe COVID-19. JAMA 324: 663-673, 2020.

86. Liu C, Martins AJ, Lau WW, Rachmaninoff N, Chen J, Imberti L, Mostaghimi D, Fink DL, Burbelo PD, Dobbs K, et al: Time-resolved systems immunology reveals a late juncture linked to fatal COVID-19. Cell 184: 1836-1857. e22, 2021.

87. Sahoo D, Katkar GD, Khandelwal S, Behroozikhah M, Claire A, Castillo V, Tindle C, Fuller M, Taheri S, Rogers TF, et al: AI-guided discovery of the invariant host response to viral pandemics. EBioMedicine 68: 103390, 2021.

This work is licensed under a Creative Commons Attribution-NonCommercial-NoDerivatives 4.0 International (CC BY-NC-ND 4.0) License. 